\author{
Nathalie Roy, $M D$ \\ Ivan M. Rebeyka, $M D$ \\ Joseph Atallah, $M D$ \\ David B. Ross, $M D$ \\ Division of Cardiac Surgery \\ Stollery Children's Hospital and \\ University of Alberta \\ Edmonton, Alberta, Canada
}

\begin{abstract}
Reference
1. Roy N, Rebeyka IM, Atallah J, Ross DB. Rapid extracorporeal life support rescue in patients undergoing the Norwood procedure. J Thorac Cardiovasc Surg. 2009;137:765-6.
\end{abstract}

doi:10.1016/j.jtcvs.2009.05.016

\section{THE LINK BETWEEN PREVIOUS PERCUTANEOUS CORONARY INTERVENTION AND CORONARY ARTERY BYPASS GRAFT RISK}

\section{To the Editor:}

We read with interest the publication by Massoudy and colleagues, ${ }^{1}$ who observed a higher rate of in hospital mortality and major adverse cardiac events in patients undergoing coronary artery bypass graft surgery with two or more previous percutaneous coronary interventions (PCIs). We wish to raise a few important issues that need to be considered when interpreting this study. First, multivariate analysis has limitations as a statistical tool in a context such as this, where a vastly disproportionate number of patients in each group could lead to inappropriate identification of meaningful predictors. Second, inasmuch as there is minimal clinical characterization of patients in this study, the reasons for initial multivessel PCI are likely to be important and may reflect patients undergoing PCI after being thought to be at too high a risk for initial coronary bypass surgery or being undertaken as urgent cases. Finally, another explanation for increased events in this cohort may be that these patients have declared themselves as a high-risk population, having had unsuccessful medical therapy and $\mathrm{PCI},{ }^{2}$ and not as a direct consequence of prior stenting alone.
Ravinay Bhindi, MBBS, PhD, FRACP, FESC $^{a}$

Oliver J. Omerod, DM, FRCP

${ }^{a}$ Department of Cardiology Royal North Shore Hospital

St Leonards

Sydney, Australia

${ }^{b}$ Department of Cardiology John Radcliffe Hospital Oxford, United Kingdom

\section{References}

1. Massoudy P, Thielmann M, Lehmann N, Marr A, Kleikamp G, Maleszka A, et al. Impact of prior percutaneous coronary intervention on the outcome of coronary artery bypass surgery: a multicenter analysis. J Thorac Cardiovasc Surg. 2009; 137:840-5.

2. Bhindi R, Van Gaal W, Testa L. Perspectives on patients with diabetes mellitus and triple-vessel disease undergoing coronary artery bypass grafting after previous percutaneous coronary intervention. J Thorac Cardiovasc Surg. 2008;135:1400.

$$
\text { doi:10.1016/j.jtcvs.2009.04.050 }
$$

\section{Reply to the Editor:}

We read with interest the remarks of Bhindi and Omerod regarding our article. ${ }^{1}$ We agree that the design of the study inherits a number of limitations. For example, the amount of variables available in the databases was very limited. Therefore, clinical characterization of patients could not be detailed. A randomized study or prospective data acquisition would certainly reduce or abolish the limitations of the retrospective study. A prospective study is, indeed, planned, but its accomplishment raises a number of organizational and structural problems.

Questioning the reasons for initial multivessel percutaneous coronary intervention (PCI) is, indeed, very interesting. According to the American Heart Association guidelines, coronary artery bypass grafting (CABG) is the recommended therapy in 3-vessel coronary artery disease. ${ }^{2}$ The increased event rate observed in the group with multiple prior PCIs thus supports published expert opinion and suggests that $\mathrm{CABG}$ should have been performed earlier. We fully agree, however, that PCI is often performed in urgent cases such as acute myocardial infarction, which, indeed, represent high-risk, if not too highrisk, cases for acute CABG.

Finally, according to our mulitcenter data, having had unsuccessful prior single PCI and medical therapy does not render a patient high risk at subsequent CABG. Only when PCI is repeatedly applied or extended to other vessel territories does the risk at subsequent CABG increase. ${ }^{1}$ Therefore, earlier referral of patients with unsuccessful PCI for CABG may prevent the transition of patients to a higher risk class and avoid disadvantageous results at subsequent $\mathrm{CABG}$.

\section{Parwis Massoudy, MD Matthias Thielmann, $M D$ Heinz Jakob, MD Department of Thoracic and Cardiovascular Surgery West German Heart Center, Essen University Hospital Essen Essen, Germany}

\section{References}

1. Massoudy P, Thielmann M, Lehmann N, Marr A, Kleikamp G, Maleszka A, et al. Impact of prior percutaneous intervention on the outcome of coronary artery bypass surgery: a multicenter analysis. J Thorac Cardiovasc Surg. 2009;137:840-5.

2. Davidoff R, Edwards FH, Ewy GA, Gardner TJ, Hart JC, Herrmann HC, et al. ACC/AHA 2004 Guideline update for coronary artery bypass graft surgery. Circulation. 2004;110:e340-437.

doi:10.1016/j.jtcvs.2009.06.002

\section{A META-ANALYSIS OF CONTROLLED STUDIES OF PREOPERATIVE STATIN THERAPY FOR PREVENTION OF POSTOPERATIVE MORTALITY IN CARDIAC SURGERY}

To the Editor:

We read with great interest an article by Tabata and associates, ${ }^{1}$ because $\mathrm{we}^{2}$ previously performed a meta-analysis of controlled studies of preoperative statin therapy for postoperative mortality in cardiac surgery. Tabata and 